\title{
Eleições e capital social: uma análise das eleições presidenciais no Brasil (2002-2006)
}

\author{
Marcello Baquero
}

Universidade Federal do Rio Grande do Sul

\begin{abstract}
Resumo: Este artigo tem como objetivo central examinar a influência do processo eleitoral presidencial em 2002 no Brasil na constituição de capital social em 2006, tanto na dimensão institucional quanto informal. Tomando como base de análise os dados do ESEB (Estudo Eleitoral Brasileiro), postulamos a hipótese de que em condições de adversidades políticas e éticas, procedimentos formais pouco incidem na formação de capital social institucional e empoderamento político dos cidadãos, levando-os a manterem predisposições negativas em relação à política. Tal situação gera uma cultura política desconfiada, propiciando a prevalência de fatores de natureza populista e subjetiva na eleição e reeleição de um candidato, neste caso, Luiz Inácio Lula da Silva.
\end{abstract}

Palavras-chaves: Eleições; Capital Social; Democracia; Empoderamento; Brasil

Abstract: This article has as a main objective analyze the influence of electoral process (presidential) in time 1 (2002), in Brazil in the constitution or not of social capital in time 2 (2006), both in the institutional dimension, as well as its informal dimension. Based upon electoral data collected by ESEB (Electoral Studies in Brazil) we postulate the hypothesis that in economic and ethical adverse conditions, formal procedures do not influence the citizens formation of social capital and political empowerment, instead it generates negative predispositions in relation to politics. In these circumstances it prevails untrusty political culture, allowing the prevalence of factors in the electoral process. In this case, in the election and reelection of Lula in 2002 and 2006 respectively.

Keywords: Elections; Social Capital; Democracy; Empowerment; Brazil 
Introdução

Desde que o período denominado de "terceira onda de democracia" (HUNTINGTON, 1994) se popularizou, pleitos eleitorais passaram a ser considerados elementos essenciais para o desenvolvimento democrático. Passados vários anos, alguns autores (LINZ e STEPAN, 1996; ROSE e SHIN, 2001) avaliaram que eleições não geram automaticamente democracias com melhor qualidade. Tal constatação sinalizou para a necessidade de estudos a respeito do fortalecimento democrático que incluíssem tanto a dimensão da cultura política quanto a abordagem institucionalista. Nesta perspectiva, avaliar como as pessoas são impactadas nos seus sistemas de crenças por experiências eleitorais prévias torna-se oportuno. As eleições presidenciais de 2002 e 2006 propiciam um campo de análise no qual podem ser observadas oscilações atitudinais em relação à democracia e ao sistema político e suas instituições.

O processo eleitoral brasileiro em 2006 gerou um cenário político bastante confuso para os analistas políticos, pois, após as denúncias de corrupção no governo Lula, certezas iniciais se transformaram em dúvidas que colocaram um ponto de interrogação em uma reeleição que parecia assegurada. Nessa direção, alguns estudiosos do tema eleitoral (CARVALHO, 2006) sugerem que, em virtude dos acontecimentos que precederam a eleição de 2006, tornou-se difícil interpretar os possíveis significados da vitória de Lula, bem como os futuros desdobramentos do seu governo no segundo mandato.

Tomando esses elementos como pano de fundo, este artigo examina as predisposições dos brasileiros em relação ao governo de esquerda (do Partido dos Trabalhadores) que, pela primeira vez, assume o poder no processo de redemocratização. Basicamente, examina se essa vitória teve alguma influência no aumento das predisposições dos brasileiros para avaliar positivamente as instituições políticas de mediação convencional entre Estado e sociedade, bem como outras organizações sociais, ou seja, se influenciou na promoção de capital social. Não é, portanto, um estudo que enfoca o resultado eleitoral ou de movimentos sociais e organizações populares, mas sim, um esforço no sentido de avaliar o impacto de uma experiência eleitoral como indutora de capital social institucional

Tendo em vista as condições favoráveis de desempenho econômico e político, o período coberto pela pesquisa pode ser caracterizado como propício ao fortalecimento da democracia brasileira (RENNÓ, 2006). Nesse contexto, duas das principais teorias sobre confiança no governo (uma centrada no engajamento cívico, outra centrada no desempenho governamental) sinalizariam que o país também mostraria níveis mais elevados de confiança, tanto institucional como interpessoal, levando os eleitores a posturas mais favoráveis em relação à totalidade do sistema político. 
BAQUERO, M. Eleições e capital social: uma análise das eleições presidenciais no Brasil...

O ideal seria trabalhar com uma pesquisa tipo painel que possibilitasse acompanhar flutuações de atitudes e de comportamentos em dois pontos no tempo. Não sendo isto viável, são comparadas duas amostras separadas por quatro anos, constituídas por sujeitos que responderam às mesmas perguntas e, através de aproximações teóricas, procurou-se determinar se houve um impacto na construção de capital social, tanto na dimensão formal quanto informal, como conseqüência do processo de habituação eleitoral.

O artigo está estruturado em três partes: a primeira faz um balanço do contexto eleitoral em 2002 e em 2006, com o objetivo de compreender as motivações políticas dos eleitores; a segunda parte analisa a configuração da cultura política brasileira do ponto de vista do dilema entre procedimentos e predisposições atitudinais em relação a assuntos políticos; a terceira parte avalia o processo de habituação eleitoral como dispositivo potencial de construção, ou não, de capital social institucional e informal.

Basicamente, busca-se compreender de que forma os gestores públicos e as instituições políticas promovem e desenvolvem a confiança, de modo a assegurar uma governança eficiente e a legitimidade do governo perante os cidadãos. Uma segunda dimensão a ser examinada diz respeito a porque, nas condições atuais dos sistemas políticos, a confiança política deve ser cultivada e mantida.

\section{O contexto eleitoral}

Para dimensionar o contexto eleitoral e melhor compreender como se deram os desdobramentos da eleição presidencial de 2006 é pertinente fazer uma retrospectiva comparativa focalizando os fatores que incidiram na vitória do PT e de Lula em 2002. Alguns dos principais elementos apontados como responsáveis pela primeira vitória da esquerda no Brasil foram: (1) a mudança programática do PT, que foi gradativamente se afastando das teses mais de esquerda e do socialismo para práticas reformistas, na tentativa de se aproximar do eleitor do centro; (2) o papel decisivo do marketing político na construção de uma imagem diferenciada de Lula, comparativamente às eleições anteriores em que ele concorreu à presidência, sobretudo através do slogan "Lula, paz e amor", que foi internalizado no sistema de crenças da maioria dos brasileiros; (3) o desgaste dos partidos de oposição, em virtude das gestões de FHC, e o esgotamento das teses neoliberais; (4) as alianças do PT com outros partidos de esquerda, bem como uma aproximação com setores mais conservadores (banqueiros e empresários); e (5) a "Carta aos Brasileiros", que visava acalmar os credores, tanto nacionais quanto internacionais, e afirmava que, caso o PT ganhasse as eleições, cumpriria os contratos assumidos e pagaria em dia os juros da dívida externa e dos contratos com o Estado. 
OPINIÃO PÚBLICA, Campinas, vol. 13, n², Novembro, 2007, p.231-259

Em 2006, as condições mudaram radicalmente. Em primeiro lugar, a figura do presidente Lula passou a assumir centralidade no processo e na negociação política em detrimento de seu partido. O principal mote utilizado na tentativa de reeleição era a defesa das políticas sociais do governo -Bolsa Família e Fome Zero-, principalmente nas áreas mais pobres do Brasil (POWER e HUNTER, 2007). Nessas regiões, Lula passou a ser conhecido como "O Pai dos Pobres". Porém, ao contrário de 2002, quando o partido teve papel fundamental, em 2006 foi a figura do candidato que relegou o partido a um segundo plano, plasmando uma velha tradição personalista no país, a qual, segundo Martins (2002), foi preservada ao longo do tempo. Tal situação fica evidenciada ao se examinar a evolução dos votos nas eleições proporcionais para o Legislativo e a votação para o presidente Lula em 2002 e em 2006.

Tabela 1

Votação nas eleições proporcionais e para presidente em 2002 e 2006

\begin{tabular}{|c|c|c|c|c|c|}
\cline { 2 - 5 } \multicolumn{1}{c|}{} & \multicolumn{2}{c|}{2002} & \multicolumn{2}{c|}{2006} & \multicolumn{1}{c}{} \\
\hline Votação & Votos & $\%$ & Votos & $\%$ & Diferença \\
\hline $\begin{array}{c}\text { Deputados federais } \\
\text { (PT) }\end{array}$ & 16.094 .000 & 18,45 & 13.990 .000 & 14,57 & -2.104 .000 \\
\hline presidente (Lula) & 39.455 .000 & 14,47 & 46.662 .000 & 48,6 & +7.207 .000 \\
\hline
\end{tabular}

Fonte: TSE. Elaborada pelo autor.

Numa retrospectiva longitudinal, os dados da Tabela 1 mostram que o PT perdeu peso no Congresso Nacional de 2002 para 2006 (13\%). Nas eleições de 2006 pode-se afirmar que foi o personalismo que saiu vitorioso, pois, a despeito dos escândalos em que o governo foi envolvido, o presidente Lula conseguiu manter e até aumentar sua base de apoio popular, garantindo um segundo mandato.

Nessa linha de análise, segundo Venturi (2007), dois conjuntos de fatores explicariam a reeleição de Lula em 2006:

1. O populismo assistencialista que caracterizaria a natureza dos programas sociais do governo federal (Bolsa Família e outras políticas compensatórias) e

2. Algum déficit dos eleitores que optaram por Lula: alienados (déficit político), desinformados (déficit cognitivo), anestesiados (déficit motivacional), cínicos ou coniventes com a corrupção (déficit moral).

$\mathrm{Na}$ mesma direção, consideramos que esses aspectos foram decisivos, principalmente a partir de 2005, momento em que a sucessão de escândalos envolvendo políticos muito próximos ao presidente Lula sinalizou, de forma contundente, que tanto a reeleição do presidente quanto a manutenção da maioria do PT no Congresso estavam comprometidas. 
BAQUERO, M. Eleições e capital social: uma análise das eleições presidenciais no Brasil...

Nesse contexto, a avaliação das instituições políticas pela população e pela opinião pública nacional e internacional era preponderantemente negativa, conforme mostram os resultados de pesquisa divulgados pelo Instituto de Estudos Anticorrupção (INEA, 2006). Segundo o estudo, em 2006, o Brasil foi classificado como o único país da América Latina a demonstrar uma corrupção sistêmico-estatal de alta nocividade social, além de já ter sido classificado como detentor de uma corrupção institucional, também de alta nocividade social. Tal classificação é considerada uma ameaça ao sistema político, ou seja, à própria democracia. Nessa perspectiva, o Estado é considerado estruturalmente um instrumento de troca, de clientelismo ou de privilégios de setores da sociedade.

A nocividade social deriva da forma como essas práticas de corrupção afetam a vida cotidiana das pessoas. A administração pública é considerada permeada por atividades prejudiciais ao funcionamento da democracia, materializada no nepotismo e no clientelismo que, conforme a literatura relevante (HOLANDA, 1980; LEAL, 1978; FAORO, 1979; DAMATTA, 1993; NUNES, 1997), são heranças da colonização portuguesa. Contemporaneamente, tanto o clientelismo quanto o nepotismo são atribuídos ao número excessivo de cargos de confiança que favorece as práticas ilícitas (AYLLÓN e GUERRERO, 2005). Para estes autores, a presença de funcionários apadrinhados por partidos governamentais nas empresas estatais é uma prática habitual no Brasil e é parte do sistema exigido pela voracidade dos seus líderes que financiam, assim, suas atividades políticas.

$\mathrm{Na}$ virada do milênio, os governos brasileiros continuam a criar cargos de confiança de forma nefasta para os interesses do país. Segundo Abramo, da Transparência Brasil, "os partidos querem cargos de direção nas estatais e na administração direta porque ali podem conduzir negócios, ou, melhor dizendo, negociatas" (ABRAMO, 2007, p.15). As instituições identificadas como as mais afetadas pela corrupção na pesquisa do INEA (2006) foram o congresso, os partidos e o governo central.

A despeito desses fatores, à medida que o pleito eleitoral de 2006 avançava, percebeu-se que a população ou não atribuía a devida importância às denúncias de corrupção, ou aceitava passivamente a total inocência do presidente em relação a atos ilícitos ou antiéticos de ministros e outros membros de seu governo. Essa situação gerou mudanças nas expectativas da mídia, da população e dos principais atores políticos de que o presidente sairia imune e fortalecido dessa situação, possibilitando a reeleição já no primeiro turno. Paradoxalmente, essas expectativas em relação à figura do presidente não se materializaram na mesma magnitude no que se refere ao PT. Pelo contrário, criou-se um sentimento de que o PT era capaz de se comportar exatamente como todos os outros partidos e, assim, não conseguiria conduzir o processo político de forma transparente e ética. O cenário eleitoral, no entanto, mostrou que a figura do presidente se manteve intacta em virtude das atitudes e comportamentos que conseguiu transmitir para o público. 
Tal postura possibilitou que a mídia atribuísse ao presidente uma capacidade inigualável de comunicação com o povo. Igualmente, se atribuía aos eleitores de baixa renda a preferência por um governante que tinha distribuído dinheiro. De qualquer forma, o que ficou claro nesta eleição foi que, apesar dos escândalos de corrupção do governo Lula, a figura do presidente assumiu um conjunto de características que o converteu, aos olhos da maioria da população, em um candidato popular imune aos escândalos políticos, o que garantiu sua reeleição.

Qual foi a imagem que Lula transmitiu ao povo brasileiro? Segundo Foucault (1977), a imagem é um signo que não representa uma coisa, mas a idéia de alguma coisa. A representação, por sua vez, é uma ponte que liga a coisa que representa à coisa representada. A possibilidade interpretativa dos conteúdos de uma imagem somente é possível de se materializar em função das condições culturais dos sujeitos, ou seja, do capital cultural que cada indivíduo tem. Acrescente-se a essa formulação a interpretação da imagem postulada por Sartori (1976), para quem a imagem partidária não é a mesma coisa que a identificação partidária. Tomando o argumento de Sartori como base, pode-se afirmar que a imagem do candidato pode ser diferente da imagem do seu partido, mesmo que os dois representem a mesma coisa. Numa cultura política frágil nas suas convicções políticas prevaleceu a imagem do candidato e não a da instituição política.

Isto não significa que outros fatores não tenham sido importantes. Por exemplo, não se pode negar a habilidade de Lula ao colocar o candidato de oposição, Alckmin, como defensor das privatizações, levando-o a adotar uma postura defensiva, lembrando a figura de FHC, o que acabou auxiliando na sua rejeição por grande parte do eleitorado. Mas, o que ficou evidente foi que, em raras ocasiões, a figura do candidato teve uma influência tão significativa no resultado eleitoral como em 2006. De fato, pode se afirmar que a personalização da política, ou seja, a proeminência da figura do candidato sobre o partido, lançando mão de estratégias de desqualificação do(s) oponente(s), prevaleceu.

Essas iniciativas e atitudes tomadas pelo presidente faziam parte de um processo de construção de sua imagem que teve como resultado entre os eleitores percepções tais como: "é uma pessoa que entende o povo"; "é uma pessoa honesta"; "não sabia e não tinha como saber o que acontecia pelas suas costas"; "se preocupa com os pobres e miseráveis" (CARVALHO, 2006).

Nessa perspectiva, houve uma clara separação por parte dos eleitores entre o governo do presidente Lula e a figura da pessoa do presidente. Esta última se manteve popular aos olhos da maioria dos eleitores. Uma imagem é algo que se pensa, supõe ou se percebe numa pessoa, objeto, situação ou conjuntura. As pessoas têm uma imagem a respeito do que seria um candidato ideal e, neste sentido, a construção da imagem do político implica em um conjunto de características que são levadas em conta pelos sujeitos em uma disputa 
BAQUERO, M. Eleições e capital social: uma análise das eleições presidenciais no Brasil...

presidencial (liderança, honestidade, capacidade de governar, entre outros). Para produzir tal imagem, é necessária uma triangulação entre o próprio candidato, a percepção dos eleitores e os meios de comunicação, que assumem um papel nesse processo de formação de imagens.

Além da imagem construída, o contexto em 2006 também foi propício para a reeleição, pois havia um otimismo moderado da população, principalmente das classes populares, em virtude do bom momento macroeconômico. Adicione-se a isso a existência de uma tendência de reeleição na América Latina: de um total de onze eleições nos últimos quatro anos, cinco, entre as quais a do Brasil, reelegeram o candidato oficial (ZOVATTO, 2007). Pode-se afirmar que, desde o retorno da democracia, a região nunca teve tantos presidentes reeleitos.

Igualmente, entre as boas notícias, podem-se apontar também, no Brasil, o moderado crescimento econômico, o avanço em algumas áreas sociais e a continuidade do processo democrático formal. Na contramão desses eventos, constata-se a crise de credibilidade que afeta a política de maneira geral e, pontualmente, os partidos políticos e o parlamento; a desigualdade na distribuição das riquezas e conseqüente concentração de renda e, sobretudo, a persistência da pobreza, conforme atestam os indicadores objetivos (CEPAL, 2005). A este respeito, Netto sugere que o resultado das eleições depende da percepção da situação econômica e política de um país. Quando a situação é economicamente precária, prevalecem os líderes que prometem soluções imediatas aos males sociais. Tal situação, segundo o autor, leva a uma maior frustração, pois "depois de algum tempo, a sociedade percebe que a rápida salvação prometida produz, depois do entusiasmo inicial, mais males do que benefícios" (NETTO, 2007, p.37). A questão que se coloca nessas circunstâncias é: como fortalecer a formação de capital social e a democracia na sua dimensão social nesse cenário onde prevaleceu o personalismo político?

\section{Paradoxo da democracia brasileira e pleito eleitoral}

Com base nos pressupostos da teoria institucionalista, nas suas várias vertentes, estabeleceu-se um consenso a respeito dos avanços na institucionalização de instrumentos e procedimentos formais de resolução dos conflitos dentro da política brasileira. Não há como negar esses progressos procedurais nos últimos anos, sendo os mais salientes o estabelecimento de eleições regulares transparentes, a existência de um sistema pluripartidário, a aceitação dos resultados eleitorais e o reconhecimento da legitimidade de quem assume o poder. Tais elementos são considerados aspectos essenciais do fortalecimento de uma nação que visa um desenvolvimento democrático sólido, duradouro e com qualidade. 
OPINIÃO PÚBLICA, Campinas, vol. 13, n², Novembro, 2007, p.231-259

Nessa direção, de acordo com Bline (2006), atualmente, os governos dispõem de um conjunto de ferramentas políticas, econômicas e sociais para fomentar a confiança social: a descentralização, o uso da tecnologia para prover um melhor acesso a serviços e informações, políticas econômicas mais eficazes e instrumentos que visam combater, por exemplo, a corrupção, bem como reformas políticas. No entanto, se é possível comemorar esses avanços formais que têm possibilitado uma certa estabilidade econômica e política, não há, por outro lado, muitas razões para festejar quando se examinam as predisposições dos cidadãos em relação à política e aos políticos pois, pesquisas realizadas nos últimos anos recorrentemente constatam um crescente distanciamento dos cidadãos da esfera política, o que, na nossa opinião, inibe seriamente o fortalecimento da democracia no país.

A esse respeito, por exemplo, Ames e Power argumentam que, passados vinte anos de experiência democrática, uma das interpretações que têm assumido proeminência a respeito da democracia brasileira destaca as instituições políticas como o calcanhar de Aquiles do novo regime. Para os autores, o Brasil é uma nação em estado permanente de crise de governabilidade: durante este período, a democracia brasileira tem enfrentado crises de inflação, corrupção e desperdício de recursos estatais, serviços sociais deficientes, violência e desigualdade social. (AMES e POWER, 2007, p.1)

Já o sistema partidário brasileiro contemporâneo, independentemente da abordagem utilizada (histórica, estrutural, behaviorista ou ideológica), pode ser descrito como altamente fragmentado, de elevada competição, volátil e debilmente institucionalizado. A maior parte dos partidos políticos brasileiros é considerada do tipo "pega tudo" e ideologicamente fraca (com exceção do PT). Este último, visto anteriormente como o partido mais transparente do Brasil, acabou se envolvendo com o escândalo da compra de votos em 2005-2006 e, em 2007, pessoas próximas ao presidente Lula envolveram-se com o tráfico de influência.

Nessa perspectiva, o elemento paradoxal da democracia brasileira contemporânea é que vive um momento de confusão política, representado, por um lado, pelo rechaço aos partidos políticos e ao Congresso e pela indiferença dos cidadãos e, por outro, pelo apoio maciço dos brasileiros ao presidente Lula, a despeito dos escândalos que supostamente envolveram funcionários do seu governo. Aliados a esses fatores, a ineficiência do Estado em promover políticas eficientes de inclusão e o reaparecimento de formas clientelísticas de fazer política redundam na deslegitimação do sistema partidário e da política em geral.

Neste cenário, ao contrário de teorias elitistas de períodos anteriores em que a participação dos cidadãos na política era considerada desnecessária (DYE e ZIEGLER, 2000), atualmente, a perspectiva dominante é de que a democracia dificilmente se consolidará sem uma base de apoio normativo aos princípios 
BAQUERO, M. Eleições e capital social: uma análise das eleições presidenciais no Brasil...

democráticos (EASTON, 1965). Nessa perspectiva, embora consolidação e legitimidade democráticas sejam conceitos diferentes, estão interligados. Segundo Rose et al (1998), o processo de consolidação dificilmente ocorrerá se estiver ausente a legitimidade pública ou se a democracia for vista como mais deficiente do que outras alternativas. Assim, a consolidação atitudinal a favor da democracia passa a ser fundamental (LINZ e STEPAN, 1996). Para vários autores, níveis estáveis e crescentes de apoio facilitam a democracia estável enquanto níveis declinantes solapam as bases democráticas e colaboram para seu colapso (MISHLER e ROSE, 1997). Retrospectivamente, constata-se que um mínimo de democracia procedural tem se mantido ao longo do tempo, o que é positivo. No entanto, não se têm verificado iguais avanços na dimensão social, pois, a crença de que após conseguir a estabilidade monetária o mercado se encarregará de resolver os problemas sociais não tem se confirmado. Nessa situação, o que parece claro é que o apoio dos cidadãos aos princípios democráticos e instituições políticas pode, de fato, influenciar a qualidade da democracia.

Por sua vez, a falta de apoio ou confiança nas instituições e nos gestores públicos pode gerar uma paralisia política e uma estagnação na evolução positiva da democracia, promovendo o individualismo em detrimento da ação coletiva e do capital social. Este é o caso, por exemplo, das instituições encarregadas de mediar as demandas da sociedade e a capacidade do Estado de respondê-las. De maneira geral, as pesquisas de opinião pública realizadas nos últimos anos no Brasil convergem para a perspectiva de que os partidos que exercem o poder experimentam um desgaste significativo que, aliado a uma frustração dos cidadãos com a falta de cumprimento das promessas eleitorais, gera cidadãos céticos e desconfiados com os governos e com a classe política. Tal situação, quando permanece inalterada, gera uma cultura política que pouco valoriza as normas democráticas, comprometendo, a longo prazo, a possibilidade de consolidação e estabilização política. Isso ocorre porque a legitimidade e durabilidade dos sistemas democráticos dependem, em grande parte, do grau de confiança que o eleitorado deposita nos governos para fazer as coisas eticamente corretas e de forma eficaz.

De maneira geral, o conceito de confiança tem sido definido em duas dimensões: (1) confiança política e (2) confiança social. A confiança política materializa-se quando as pessoas acreditam que os gestores públicos e as instituições políticas trabalharão em beneficio da coletividade e não do interesse individual. Argumenta-se, neste sentido, que "a confiança política é um indicador central dos sentimentos públicos subjacentes em relação à política" (SHI, 2001, p. 401). Do ponto de vista da confiança política, dois desdobramentos conceituais são utilizados: confiança difusa e confiança específica. O primeiro se refere a valores simbólicos e ao senso de pertencer ao sistema político e o segundo diz respeito às 
avaliações que os eleitores fazem das instituições políticas específicas (CITRIN, 1974). A confiança social refere-se à confiança dos cidadãos uns nos outros enquanto membros de uma comunidade social, sendo esta dimensão inseparável da confiança política. O principal proponente desta linha de análise, Putnam (2000), argumenta que a confiança interpessoal contribui para aumentar a confiança social em uma sociedade. A unidade central que dá a coesão entre as pessoas para desenvolver sentimentos de confiança recíproca, segundo Putnam, é o nível de associatividade num determinado contexto.

A associatividade como elemento estrutural de confiança interpessoal depende, também, da percepção que o cidadão tem a respeito do atendimento pelo Estado e pelas suas instituições das suas necessidades naturais essenciais. No caso do Brasil, sua situação socioeconômica ainda precária torna difícil a possibilidade de um governo satisfazer as necessidades e expectativas da maioria da população, gerando um descontentamento endêmico. Tal situação de insatisfação gera um padrão de comportamento eleitoral que geralmente desemboca na derrota de quem está no poder, a não ser que surja alguma variável que altere este padrão. Por exemplo, a continuação do Plano Real e a estabilidade econômica, aliadas à alteração do dispositivo constitucional que não permitia a reeleição, possibilitaram um segundo mandato para Fernando Henrique Cardoso. No caso de Lula, foi a Bolsa Família que ajudou decisivamente a garantir um segundo mandato. Essas reeleições ocorreram, segundo alguns autores (PINHEIRO, MALAK e KAHN, 1993), a despeito de a democracia ainda se mostrar frágil, já que direitos econômicos básicos não podem ser garantidos. Dessa forma, compreender como os eleitores constroem seus imaginários coletivos em relação à política torna-se vital.

Assim, embora muitas atitudes sejam essenciais para a efetividade e vitalidade das instituições democráticas, algumas são registradas como sendo as mais importantes. Desde 1950, a confiança no governo e a eficácia política estão entre os indicadores mais utilizados, representando sentimentos de legitimidade e responsividade do sistema, percepção de uma razoável honestidade dos resultados governamentais. As questões utilizadas para avaliar estas dimensões centram-se em três aspectos: eficácia política, confiança institucional e depolarização (oscilação de atitudes no sentido negativo de uma eleição para outra).

No Brasil, existem evidências de que os cidadãos estão crescentemente insatisfeitos com o governo, embora o padrão de satisfação tenha mostrado aumentos e declínios ao longo do tempo (BAQUERO, 2000). Essas oscilações permitem modelar os eleitores enquanto indivíduos que possuem uma função de utilidade negativamente relacionada, ou seja, o governo é definido em termos das políticas e atividades governamentais oficiais e do comportamento dos representantes eleitos. Isso possibilita avaliar se depois de experimentar uma eleição presidencial, os cidadãos com experiência eleitoral (votar e se envolver em 
BAQUERO, M. Eleições e capital social: uma análise das eleições presidenciais no Brasil...

campanhas eleitorais) são os mais prováveis de mostrarem orientações democráticas favoráveis. O foco está em como a experiência de envolvimento em associações convencionais e comunitárias afeta as mudanças pré e pós eleitorais em atitudes favoráveis ao processo democrático por meio do capital social.

\section{Eleições e Capital Social}

$\mathrm{Na}$ democracia representativa contemporânea, o que está em jogo é a natureza da atividade de representação, e não os procedimentos e arranjos institucionais que induzem à representação política. Os arranjos formais que iniciam, capacitam e terminam na representação política têm se mantido estáveis ao longo dos últimos anos, conforme assinalam PRZEWORSKI, STOKES e MANIN (1999):

1.Os governantes são escolhidos por meio de eleições;

2. Enquanto os cidadãos são livres para discutir, criticar e demandar todo o tempo, eles não têm a capacidade para obrigar o governo a cumprir o prometido;

3.Os governantes são eleitos periodicamente.

A questão, portanto, é saber se as pessoas eleitas para cargos políticos agem como representantes da população e se isto é suficiente para obrigar os governos a agirem de forma representativa, pois as motivações a ações dos líderes políticos não podem ser conhecidas com antecedência e certeza (PRZEWORSKI, 1991). Nesta perspectiva, a confiança emerge como um dos principais dispositivos na construção da legitimidade e sustentabilidade de um sistema político.

Um governo é considerado representativo se age com base no melhor conhecimento disponível e se os indivíduos estão suficientemente informados de que cada um deles ou a média deles tem uma probabilidade maior de alcançar a decisão correta (eficácia interna dos eleitores). Este conhecimento é revelado pelo veredicto da maioria dos eleitores no pleito eleitoral.

$\mathrm{Na}$ perspectiva institucional, as eleições são consideradas como os principais meios para enaltecer o poder dos cidadãos via controle popular. As eleições são o elemento essencial da democracia representativa, e, por meio delas, os cidadãos expressam suas opiniões políticas. Uma participação desigual coloca a democracia em risco. Atualmente, constata-se que a participação política das pessoas manifesta-se de formas diferentes (convencional, não convencional, comunitária e social). Igualmente constata-se que, de maneira geral, do ponto de vista de quaisquer dos indicadores utilizados para aferir este tema, o interesse e a participação propriamente ditos estão em processo de declínio (LATINOBARÓMETRO, 2005), e que tal declínio não é indicativo da institucionalização de uma base normativa de apoio à democracia, como resultado 
do processo de habituação a procedimentos formais institucionalizados. Pelo contrário, o afastamento deliberado das pessoas da arena política encontra suas raízes na decepção e no desencantamento com as promessas não cumpridas pelos políticos que têm assumido o poder no período pós-autoritarismo.

Decorrente dessa situação, o crescente repúdio à forma como os gestores públicos utilizam os recursos públicos e às práticas de corrupção têm produzido predisposições antagônicas em relação às instituições políticas de caráter estrutural. Quando fatores estruturais negativos dominam o imaginário coletivo cotidiano, há uma propensão à reprodução de velhos vícios políticos (fisiologismo, nepotismo, corrupção, clientelismo e patrimonialismo), a despeito dos avanços poliárquicos. A situação na qual o regime democrático convive pacificamente com um Estado oligárquico pode ser denominada democracia inercial (BAQUERO, 2006).

Nesse tipo de democracia, constatam-se não somente os avanços formais da democracia, mas também a dinamização da economia em aspectos pontuais como: aumento das exportações, aumento da produtividade industrial e aumento da capacidade tributária do Estado. Paradoxalmente, esses aspectos não se traduzem em mais investimentos sociais capazes de melhorar a qualidade de vida das pessoas. A grande maioria continua a ser marginalizada das políticas sociais, ou contemplada num sentido assistencialista, permanecendo numa situação de vulnerabilidade e manipulação política. A classe média, espinha dorsal de qualquer sistema democrático, tem sido a mais afetada na sua qualidade de vida e no aumento abusivo de tributos que, ao invés de produzirem melhores condições de vida, reduzem seu poder aquisitivo. Esta situação leva uma parcela significativa desse setor a experimentar um novo tipo de pobreza dura.

Nessas circunstâncias, a possibilidade de socializar atitudes e comportamentos de apoio às instituições democráticas é difícil. A inércia se manifesta, portanto, numa situação de avanços econômicos e formais em benefício do Estado e de uma parcela minoritária da população, enquanto a maioria continua a enfrentar os dramas difíceis da vida cotidiana. A ineficiência do Estado em desenvolver políticas inclusivas gera um hiato onde as predisposições e, portanto, a cultura política do país continuam a depender do "jeitinho" do clientelismo e do patrimonialismo. Nessas circunstâncias, uma parte significativa do eleitorado passa a optar por candidatos com base em aspectos preponderantemente subjetivos e emocionais. Tal parece ter sido a situação das eleições em 2006.

Da mesma maneira, as inovações políticas desenhadas para produzir um empoderamento institucional se esgotam em si próprias, ou seja, garantem a sobrevivência dessas instituições (partidos, congresso entre outras), mas têm como corolário, paradoxalmente, o "desempoderamento" dos cidadãos, na medida em que os afastam da arena política. Novas tecnologias midiáticas também não têm contribuído como se esperava para tornar os cidadãos mais participativos. Por exemplo, os meios de 
BAQUERO, M. Eleições e capital social: uma análise das eleições presidenciais no Brasil...

comunicação, ao mesmo tempo em que agem como instâncias de fiscalização dos atos políticos e os denunciam, parecem não ter nenhuma incidência em um maior estímulo à participação e ao envolvimento político. Tal fenômeno pode ser explicado pelo fato de que a informação política divulgada é preponderantemente negativa, deteriorando o ambiente político (PHARR, PUTNAM e DALTON, 2000) e não contribuindo para a efetivação de um princípio normativo da democracia - uma decisão bem informada (ARNOLD, 2004).

Uma explicação para este fenômeno radica na profissionalização e economização da política, que relega, para posição secundária, o "empoderamento" dos cidadãos, (re)produzindo uma cultura política pouco afeita aos valores democráticos, não por não acreditar neles, mas por experiências empíricas onde essas instituições não têm funcionado para o benefício dos que mais delas necessitam. Nessa perspectiva, a probabilidade de a maioria dos cidadãos apresentar baixa "eficácia interna" (percepção de que podem influenciar a política) e baixa "eficácia externa" (a percepção de que o governo responde às demandas da população) aumenta. O significado da eficácia política importa na medida em que pode fornecer subsídios para compreender uma ampla gama de predisposições atitudinais e comportamentos na arena política. Finkel (1985) considera que a eficácia interna representa o sentimento de uma pessoa de que realmente pode influenciar a política. Para Craig (1979), a "eficácia externa" impacta a confiança política e, para Shaffer (1981), a participação eleitoral. No caso brasileiro, parece que os processos eleitorais produzem mais "eficácia externa" do que "eficácia interna", gerando uma assimetria de desenvolvimento entre crescimento econômico, por um lado, e estagnação normativa de apoio à democracia, por outro. Tal situação é propícia para a institucionalização do personalismo, em detrimento das instituições políticas.

Assim, do ponto de vista de construção de capital social institucional, a participação em eleições presidenciais, presume-se, pode promover sentimentos de respeito à legitimidade do sistema político e à capacidade de resposta do governo, fomentando a eficácia externa, mas não a eficácia interna. A ausência da eficácia interna inibe a valorização da participação como valor em si, afetando negativamente a promoção do engajamento cívico, pois desvaloriza o aspecto educativo da participação num espectro mais amplo.

Esse paradoxo revela um dilema da democracia brasileira contemporânea, o conflito entre uma política baseada na igualdade e na liberdade - mais especificamente o conflito entre uma política baseada na igualdade de voz - e uma economia baseada na desigualdade de recursos. Na medida em que a voz depende de recursos, um mercado político não regulado garante a desigualdade política. A nova tecnologia tem dado àqueles com mais recursos acesso a mais voz. Como resultado, muitas eleições têm se transformado para os cidadãos em um exercício na escolha entre dois blocos de poder que representam interesses, senão iguais, bastante semelhantes, a despeito de uma retórica ideológica tradicional. 
OPINIÃO PÚBLICA, Campinas, vol. 13, n², Novembro, 2007, p.231-259

Os últimos pleitos eleitorais no Brasil têm mostrado que, a cada inovação tecnológica produzida pelos especialistas, o custo de acesso a essas inovações tem aumentado linearmente. Na ausência de partidos fortes ou regulamentações públicas das atividades de campanha, os candidatos negociam diretamente com os consultores. A luta pelo poder não é mais uma atividade organizacional, mas uma tarefa empresarial. Atualmente, arrecadam-se recursos para pagamento de consultores e deixa-se em segundo plano a lealdade ao comando da organização. Nas eleições de 2002 e de 2006, um dos aspectos fundamentais da campanha e sucesso eleitoral do PT foi o marketing político comandado por Duda Mendonça. Esse fenômeno ajuda a explicar a institucionalização de relações terciárias (percepção de relação direta ente o gestor público e o eleitor) no sistema político brasileiro, diminuindo as possibilidades de os partidos serem os catalisadores de identidades políticas coletivas.

Na medida em que o marketing político suprime a participação militante é, portanto, natural que os políticos dêem mais atenção àqueles que os ajudaram materialmente a colocá-los no poder. Este padrão de participação significa que a maior parte do eleitorado, se não o seu conjunto, é consistentemente deixada de fora do cálculo político ou incluída de forma assistencialista e populista. Nessas circunstâncias, o personalismo se fortalece.

Os benefícios das eleições podem ser indiretos. Embora eleições ofereçam aos cidadãos um mecanismo institucional para expressar sua aprovação para o exercício continuado da liderança, elas também proporcionam aos cidadãos os meios de afirmar sua fé na validade e legitimidade do sistema político através da participação. Nesta perspectiva, as eleições podem ser consideradas como um recurso para o governo, proporcionando a legitimidade ao sistema político e um "espaço" para as autoridades eleitas que trabalham nele. Tal situação fica evidente quando se examinam as distribuições agregadas pós-eleitorais de vários indicadores de apoio difuso, os quais se mostram mais elevados do que no período pré-eleitoral.

Um dos principais indicadores da saúde democrática de uma nação se refere, portanto, a como as pessoas se posicionam em relação à democracia em um sentido difuso. A Tabela 2 examina essas predisposições. 
BAQUERO, M. Eleições e capital social: uma análise das eleições presidenciais no Brasil...

Tabela 2

Opinião sobre a democracia (\%)

\begin{tabular}{|c|c|c|}
\cline { 2 - 3 } \multicolumn{1}{c|}{} & 2002 & 2006 \\
\hline $\begin{array}{c}\text { A democracia é sempre melhor que } \\
\text { outra forma de governo }\end{array}$ & 69,3 & 71,7 \\
\hline $\begin{array}{c}\text { Em algumas situações a ditadura é } \\
\text { melhor que a democracia }\end{array}$ & 18,9 & 14,2 \\
\hline Tanto faz/nenhuma das duas é melhor & 2,4 & 6,9 \\
\hline NS & 9,3 & 7,1 \\
\hline Total & 100 & 100 \\
\hline
\end{tabular}

Fonte: ESEB, $2002(n=2491), 2006(n=995)$.

Os dados da Tabela 2 mostram o apoio difuso à democracia: entre 2002 e 2006, as porcentagens de apoio à democracia mantiveram-se constantes (69,3 e 71,7, respectivamente). Igualmente, houve uma diminuição significativa de 2002 $(18,9 \%)$ para $2006(14,2 \%)$ daqueles que consideraram a ditadura melhor em algumas situações. Obviamente que uma coisa é rejeitar práticas autoritárias e outra inteiramente diferente é institucionalizar a crença na democracia, a qual exige cidadãos politizados.

Atribui-se à recorrência de pleitos eleitorais uma dinâmica socializadora positiva. A expectativa é que, de uma eleição para outra, o estoque existente de capital social público aumente, proporcionando o estímulo, social e político, que gera e reafirma a fé no sistema político. Argumenta-se que um determinante importante desse aumento de confiança num sentido pós-eleitoral de orientações democráticas deriva do nível de envolvimento dos cidadãos em atividades, organizações políticas e em eleições prévias.

Não há, entretanto, a não ser em discussões teóricas, evidência empírica dessa relação. Desse modo, à medida que a democracia poliárquica, com seus procedimentos e regras formais, não têm conseguido, segundo pesquisas de opinião, fornecer as bases sobre as quais se produza uma base normativa de apoio sólido à democracia, cientistas políticos têm voltado suas atenções a dispositivos alternativos de motivação política dos cidadãos. A idéia de que não se podia prescindir de um Estado mínimo e confiar tudo ao mercado está abrindo espaço para uma concepção que aponta para uma aliança entre um Estado capaz e com sensibilidade social, empresas socialmente responsáveis e uma sociedade civil plenamente mobilizada (KLIKSBERG, 2006). Como as organizações convencionais de mediação política parecem, cada vez mais, padecer de avaliações negativas do seu desempenho e questionamentos sobre a sua indispensabilidade, outros dispositivos de engajamento político têm emergido. 
OPINIÃO PÚBLICA, Campinas, vol. 13, n², Novembro, 2007, p.231-259

Dessa maneira, observa-se, nos últimos anos, uma proliferação de organizações constituídas desde a base por iniciativa de cidadãos. Ao mesmo tempo, alguns autores têm argumentado que cresce o interesse das novas gerações em formar parte de tais organizações. De acordo com dados do Instituto de Serviço Global da Universidade de St. Louis (2004), existem atualmente na América Latina não menos do que um milhão de organizações da sociedade civil (OSC) atuando nos campos de desenvolvimento comunitário, educação e capacitação, participação cívica, saúde, necessidades básicas, meio ambiente, direitos humanos, processos de paz e serviços de emergência (KLIKSBERG, 2006, p.2). Tais iniciativas têm propiciado o desenvolvimento da teoria de capital social e a discussão do seu papel no desenvolvimento político-econômico de uma nação.

A teoria do capital social nas suas diferentes perspectivas (Coleman, Bourdieu, Putnam) basicamente postula a influência da vida social (normas, redes e confiança) para estimular uma participação integrada e coesa entre os membros de uma comunidade na busca de objetivos comuns. Tal comportamento toma como base o desenvolvimento de sentimentos e comportamentos de natureza cooperativa, colaborativa e solidária. Esse comportamento não sugere que os conflitos sejam permanentemente eliminados da comunidade, mas aponta para a possibilidade de um agir comunitário mais eficiente e com retornos materiais concretos. Se os resultados da ação coletiva são visíveis e tangíveis, então, a lógica formal sugere que poderiam ser estabelecidas bases para comportamentos coletivos, mesmo na presença de conflitos entre os membros, ou seja, o poder da união da comunidade colocaria em segundo plano os antagonismos e rivalidades tradicionais. O resultado traduzir-se-ia em sistemas com potencial para melhorar sua qualidade de vida, e, ao mesmo tempo, propiciaria condições para o estabelecimento de uma democracia com melhor qualidade.

Dessa maneira, os resultados da ação coletiva recíproca auxiliariam o processo de construção de capital social além da dimensão puramente institucional, partindo da premissa de que os avanços na área institucional, neste caso as eleições, incidem positivamente no "empoderamento" dos cidadãos. No entanto, os indicadores de capital social informal (afiliação a sindicatos e a organizações profissionais) não confirmam esta tendência. 
BAQUERO, M. Eleições e capital social: uma análise das eleições presidenciais no Brasil...

Sociedade civil, capital social e democracia eleitoral

Tanto a teoria da sociedade civil quanto a de capital social argumentam que uma democracia está baseada em redes sociais formais e informais na comunidade e que operam independentemente do governo, e ambas as teorias enfatizam as bases sociais da democracia, principalmente as virtudes cívicas associadas a redes densas e fortes de associações voluntárias. Dessa forma, o aspecto central da teoria do capital social e da sociedade civil está centrado no indivíduo e não no nível racional agregado. A teoria do capital social tem como premissa a institucionalização de um círculo virtuoso entre elevada confiança, instituições sociais bem estabelecidas, um bom governo e um forte apoio popular, os quais ajudam a sustentar a confiança social entre os cidadãos, a promover a participação comunitária e cívica e o encorajamento na realização de atividades coletivas para o bem comum.

Níveis elevados de confiança social generalizada são acompanhados pelo respeito à propriedade individual e às liberdades e aos direitos civis, pela cooperação cívica, por uma sociedade democrática estável e por elevados níveis de confiança nas instituições políticas. Newton encontrou evidências empíricas a respeito dessas correlações, embora elas não sejam muito fortes (NEWTON, 2001,p.3).

De acordo com Putnam (1976), a maior parte dos estudos enfocam as organizações voluntárias como representantes de capital social. O argumento é que áreas com redes amplas e densas que se entrecruzam, produzem, direta ou indiretamente, valores de colaboração entre as pessoas. Decorrente dessa situação, em áreas onde tais características estão ausentes, a tendência é o desenvolvimento de predisposições e comportamentos pouco afeitos aos valores democráticos, resultando, assim, na institucionalização da falta de confiança institucional e interpessoal.

Vários estudos têm apresentado correlações positivas entre capital social e participação política na América Latina (SELIGSON, 1999). A evidência empírica sugere que um maior envolvimento em organizações formais e informais encoraja a participação política. Booth e Richard (1998) também encontraram correlações significativas entre ativismo da sociedade civil e formação de capital social e político. Kliksberg (2001), por sua vez, aponta três experiências de cooperação comunitária como base de construção de capital social, são elas: a experiência de Villa el Salvador, no Peru; as feiras de consumo popular em Barquisimeto, Venezuela e a experiência do orçamento participativo em Porto Alegre, Brasil.

A base para compreender a produção de capital social é o envolvimento das pessoas em atividades coletivas de benefício mútuo e o fato de que este não seria alcançado por meio das organizações convencionais de mediação política. 0 pressuposto é que o envolvimento dos cidadãos neste tipo de organização gera bens 
tangíveis que agem como dispositivos de construção de uma consciência crítica e participativa e que, a médio e longo prazo, pode incidir no estabelecimento não só de uma base normativa de apoio à democracia, mas, sobretudo, no processo de amadurecimento democrático, propiciando a solidificação de um sistema político orientado não somente para a dimensão formal, mas também para a dimensão social.

Discutindo os aspectos relacionados com o impacto do capital social na vida cotidiana, Klesner (2002) sustenta que se níveis elevados de capital social não ajudam a promover mais participação política e uma experiência democrática mais rica, então, as preocupações sobre o significado do seu declínio não seriam tão relevantes. Porém, se capital social encoraja a atividade política, encontrar mecanismos que possibilitem um maior engajamento dos cidadãos na política pode se constituir em meios efetivo de promoção de uma democracia com melhor qualidade.

Enquanto interações face a face constroem confiança e cooperação entre membros do grupo, os benefícios, pode-se dizer, afetam a sociedade como um todo. Normas de reciprocidade, confiança e afiliação inculcadas pelas "democracias pequenas" de associações voluntárias se espraiam para o sistema político. Mill referia-se às práticas em associações voluntárias como os meios de educação mental, enquanto Tocqueville pensava as associações como sendo "a grande escola" da democracia americana. Tal escola democrática possibilitou o surgimento de apoio difuso pelas instituições políticas e sociais de alto nível. De maneira semelhante à educação convencional, a atividade associativa molda as predisposições democráticas das pessoas via socialização, aquisição de conhecimento e experiência compartilhada. Isto sugere que os cidadãos que possuem práticas eleitorais devem aumentar suas orientações democráticas depois de terem experimentado mais uma eleição presidencial.

Se a "habituação eleitoral" tivesse um impacto positivo nas predisposições dos eleitores em eleições posteriores, produzindo capital social institucional, tais motivações atitudinais seriam acompanhadas por julgamentos positivos dos procedimentos formais. Entretanto, esta não parece ser a evolução das eleições brasileiras entre 2002 e 2006, conforme o Gráfico 1 sugere. 
BAQUERO, M. Eleições e capital social: uma análise das eleições presidenciais no Brasil...

Gráfico 1 - Avaliação de procedimentos poliárquicos

Dimensão negativa (\%)

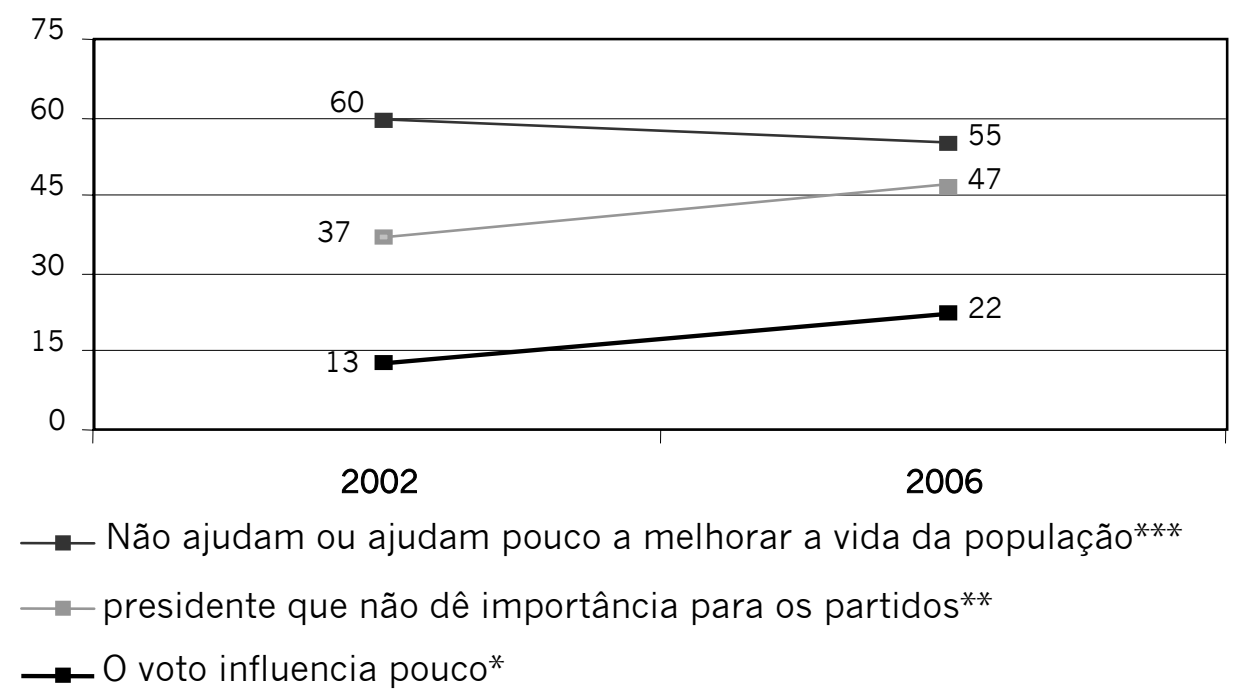

Fonte: ESEB, 2002 e 2006.

presidente não deve dar importância para partidos n $2002=2495$, n $2006=907$

$O$ voto influencia pouco o que acontece no país n 2002=1878, n 2006=982

As eleições presidenciais não ajudam ou ajudam pouco a melhorar a vida da população $n$ $2002=2465$, n 2006 $=975$

* Opinião sobre a influência do voto no que acontece no país

** Opinião sobre melhor relação entre o presidente da república e os partidos

*** Opinião sobre as eleições presidenciais

Constata-se uma leve diminuição da percepção dos cidadãos de que as eleições presidenciais não ajudam a melhorar a vida da população $(60 \%$ em $2002 \mathrm{e}$ $55 \%$ em 2006, respectivamente). No item relacionado ao presidente não dar importância ao partido, outro padrão se materializa: a porcentagem daqueles que responderam que o presidente não deve dar importância ao partido político aumentou de 37\% em 2002 para 47\% em 2006. Tal situação se repete para a questão da influência do voto para o que acontece no Brasil: os dados mostram que o número de entrevistados com opinião negativa aumentou de 13\% em 2002 para 22\% em 2006.

Esses dados sinalizam de forma contundente que a hipótese institucionalista que atribui um papel socializador positivo a experiências eleitorais em tempo 1 para tempo 2, pelo menos no caso das eleições presidenciais no Brasil de 2002 para 2006, não se confirmam. Pelo contrário, as avaliações negativas aumentaram no período pós-eleitoral. Naturalmente, não se pode negligenciar o papel interveniente de aspectos relacionados com o pleito eleitoral, tais como: a corrupção, denúncias de malversação de recursos públicos (congresso e partido), bem como um sentimento 
generalizado de insegurança e incerteza da população. Quando essas variáveis são segmentadas, verificam-se oscilações por sexo, renda e escolaridade, porém, o que interessa aqui do ponto de vista da constituição de capital social institucional pré e pós-eleitoral reforça a idéia de que a eficácia interna dos cidadãos, no período examinado, experimenta um declínio. Este declínio sugere a manutenção de bases precárias para o fortalecimento de uma cultura política participativa.

Existem pelo menos três outros mecanismos por meio dos quais o apoio público à democracia favorece uma democracia com melhor qualidade. Em primeiro lugar, a democracia pressupõe uma cultura cívica caracterizada pela lealdade dos cidadãos aos princípios democráticos básicos: confiança mútua, cooperação e moderação entre as elites e os públicos bem como as normas democráticas participativas.

Em segundo lugar, a democracia supõe não só um apoio aberto, ou seja, a afirmação verbal das preferências pela democracia, como também um apoio intrínseco aos valores democráticos tais como liberdade, livre expressão, tolerância da diversidade, confiança interpessoal e satisfação com a vida. O apoio explícito à democracia é um pouco mais do que o comprometimento retórico e exige que seja complementado com valores democráticos intrínsecos. Além do mais, o apoio aos valores democráticos intrínsecos fortalece a democracia efetiva, definida como a medida de respeito das elites políticas à lei dentro dos parâmetros das liberdades cívicas e políticas. Apoio difuso à democracia, por outro lado, é insignificante, porém positivamente relacionado às medidas de democracia efetiva.

No que se refere ao aspecto de fiscalização social, nos últimos anos, tem se verificado uma tendência crescente de surgimento de associações civis, ONG's e movimentos sociais que funcionam de forma semelhante aos meios de comunicação para monitorar os gestores públicos e torná-los responsáveis perante a lei, expor casos de corrupção e convencer as instituições a exercitar suas funções de fiscalização horizontal.

Em terceiro lugar, a erosão do apoio à democracia pode estar relacionada ao surgimento do populismo ou "neo-populismo", o qual tem sido identificado pela qualidade da democracia na época pós-autoritária. Líderes neo-populistas têm conseguido o apoio em virtude de seus posicionamentos discursivos anti-sistema e anti-elite. Uma vez no poder, eles freqüentemente passam a utilizar decretos-leis e poderes plebiscitários para burlar os legislativos e tomam ações para deliberadamente fragilizar as cortes supremas, as burocracias e outras instituições que possam eventualmente questionar sua autoridade. Na busca de apoio institucional, tais líderes estabelecem pactos com forças conservadoras, tecnocratas, ou setor privado, investidores internacionais ou algum tipo de troca dessa natureza. O apoio popular a neo-populistas na forma de votos ou expectativas econômicas está bem documentado; porém, essas expectativas e comportamentos 
BAQUERO, M. Eleições e capital social: uma análise das eleições presidenciais no Brasil...

podem revelar a ponta do iceberg na base do qual reside o pouco apoio à governança democrática e o fortalecimento do personalismo em detrimento das instâncias poliárquicas.

Nesta perspectiva, torna-se relevante examinar a forma como os brasileiros avaliaram as instituições políticas e não-políticas nas eleições presidenciais de 2002 e de 2006 (Gráfico 2).

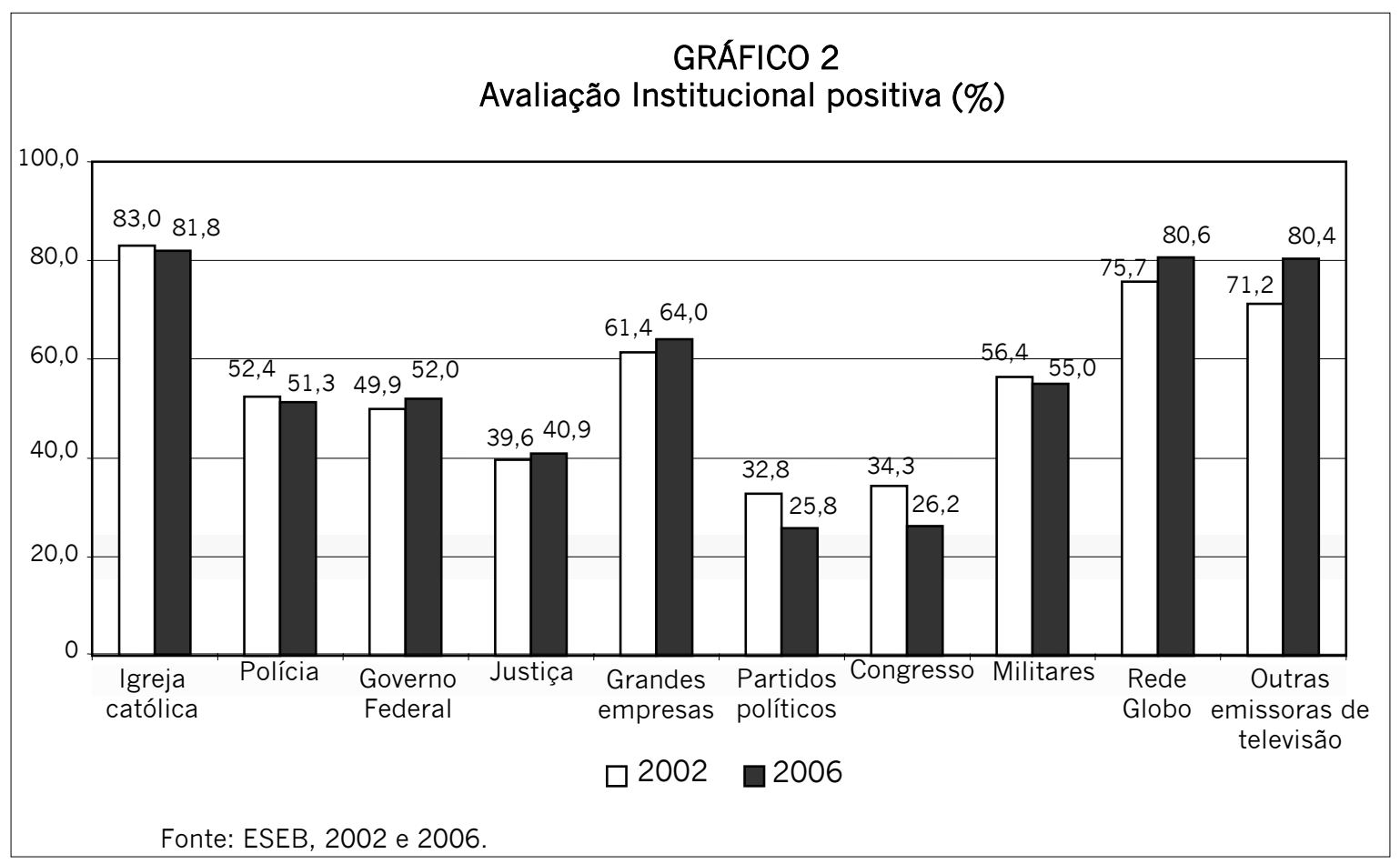

Consistente com os dados anteriores de capital social, confirmam-se as avaliações negativas das instituições políticas. Tanto o Congresso experimenta uma redução dos índices de avaliação de 32,8\% em 2002 para 25,8\% em 2006, quanto os partidos caem de 34,3\% em 2002 para 26,2\% em 2006. Tais tendências parecem atestar o pouco apreço que os cidadãos mostram por essas instituições, elementos-chave em um processo de construção democrática sólida. Comparando essas porcentagens com as opiniões a respeito dos meios de comunicação, constata-se que essas instâncias melhoraram sua imagem positiva de 2002 para 2006. Do mesmo modo, a Igreja Católica é avaliada positivamente por, em média, $82 \%$, no período 2002-2006. As outras organizações se mantêm em um patamar intermediário, entre $40 \%$ e $60 \%$ nos dois pleitos eleitorais. 
OPINIÃO PÚBLICA, Campinas, vol. 13, n², Novembro, 2007, p.231-259

Esses dados apontam para uma situação já conhecida no país e que parece se reproduzir na virada do milênio, qual seja, um declínio progressivo da avaliação das instituições convencionais de mediação política (Congresso e partidos), que não se constituem, dessa forma, em dispositivos de "empoderamento" institucional. Em tais circunstâncias, a probabilidade de solidificar a democracia na sua dimensão normativa é reduzida.

Um dos principais indicadores de apoio à democracia do ponto de vista da teoria da cultura política é o grau de satisfação dos cidadãos com o funcionamento da democracia. Existem, no entanto, dúvidas em relação ao exato significado desta dimensão. O quê exatamente ela mede? Pensamos que para responder a esta pergunta é necessário contextualizá-la dentro do cenário econômico e social no qual a indagação é proposta. No caso do Brasil, a satisfação com a democracia deve se dar simultaneamente tanto do ponto de vista social quanto formal. Na perspectiva do funcionamento da democracia formal, é pertinente separar apoio difuso, ao qual a Tabela 2 se refere, de apoio específico (EASTON, 1965). Este tipo de apoio diz respeito a uma avaliação de nível de satisfação dos cidadãos com o funcionamento do sistema democrático. Estes dados estão apresentados na Tabela 3.

Tabela 3

Nível de satisfação com o funcionamento da democracia (\%)

\begin{tabular}{|c|c|c|}
\cline { 2 - 3 } \multicolumn{1}{c|}{} & 2002 & 2006 \\
\hline Nada satisfeito & 25,8 & 14,3 \\
\hline Pouco satisfeito & 35,1 & 26,7 \\
\hline Nem satisfeito nem insatisfeito & 1,8 & 11,6 \\
\hline Satisfeito & 25,3 & 38,6 \\
\hline Muito satisfeito & 5 & 4,1 \\
\hline Não sabe o que é democracia & 4,8 & - \\
\hline NS & 1,7 & 4,3 \\
\hline NR & 0,5 & 0,4 \\
\hline Total & 100 & 100 \\
\hline
\end{tabular}

Fonte: ESEB, $2002(n=2513), 2006(n=1000)$.

Estar insatisfeito com o funcionamento da democracia não significa necessariamente apoiar alternativas ao sistema democrático. Cidadãos podem ter tido, em algum momento, experiências pouco positivas em repartições públicas que os levaram a desenvolver predisposições negativas em relação às instituições governamentais e, por decorrência, à democracia. No entanto, isso não implica o apoio explícito a rupturas institucionais, mas o aspecto negativo da existência desta 
BAQUERO, M. Eleições e capital social: uma análise das eleições presidenciais no Brasil...

dimensão é que as predisposições de apoio à democracia em termos gerais não estão solidificadas, e os cidadãos são vulneráveis a apelos populistas e demagógicos.

Ao indagar aos brasileiros sobre o nível de satisfação com o funcionamento da democracia (Tabela 3), constata-se que houve uma redução significativa de 60.9\% em 2002 para $41 \%$ em 2006 entre aqueles que estavam insatisfeitos ou pouco satisfeitos. Em um nível geral de satisfação, a percentagem aumentou de 25,3\% (em 2002) para 38,6\% (em 2006), enquanto aqueles muito satisfeitos diminuíram de 5\% em 2002 para 4\%, em 2006. Esses dados pouco auxiliam na determinação, ou não, de um processo de institucionalização efetivo de democracia. $\mathrm{Na}$ verdade, expressa o caráter híbrido de cultura política e a influência de fatores conjunturais em pleitos eleitorais. A natureza híbrida das predisposições atitudinais dos brasileiros sugere estar em andamento um processo relativamente crescente de satisfação de eleição para eleição, quando se examinam, pontualmente, as respostas às perguntas relacionadas com as práticas partidárias e sobre os candidatos a presidente (Tabela 4).

Tabela 4

Avaliação de partidos e candidatos

\begin{tabular}{|c|c|c|c|c|}
\cline { 2 - 5 } \multicolumn{1}{c|}{} & \multicolumn{2}{c|}{2002} & \multicolumn{2}{c|}{2006} \\
\cline { 2 - 5 } \multicolumn{1}{c|}{} & SIM & NÃO & SIM & NÃO \\
\hline $\begin{array}{c}\text { Algum partido representa sua } \\
\text { maneira de pensar? }\end{array}$ & 39 & 57 & 28 & 68 \\
\hline $\begin{array}{c}\text { Algum candidato a presidente desta } \\
\text { eleição representa sua maneira } \\
\text { de pensar? }\end{array}$ & 64 & 36 & 48 & 52 \\
\hline
\end{tabular}

Fonte ESEB, $2002(n=2499), 2006(n=991)$.

Os resultados da Tabela 4 mostram a descrença que os brasileiros têm dos partidos políticos. Nas eleições de 2002, que marcaram a vitória de um candidato de esquerda e considerado do povo, somente 39,0\% responderam que algum partido representava sua forma de pensar, enquanto $57,0 \%$ não pensavam dessa maneira. Em 2006, a despeito da reeleição do presidente Lula, somente $28 \%$ dos brasileiros pensavam que algum partido representava sua forma de pensar, ao passo que $68 \%$ não pensavam dessa forma. 
OPINIÃO PÚBLICA, Campinas, vol. 13, n², Novembro, 2007, p.231-259

Quanto à figura do candidato, em 2002, era maciço o apoio à figura de Lula, considerado como o representante do pensamento de $64 \%$ dos entrevistados. Em 2006, essa porcentagem caiu para $48 \%$. O que se pode concluir desses dados é que, enquanto em 2002 partido e candidato conseguiram a vitória para o Planalto, em 2006 foi a figura de Lula que conseguiu a reeleição, a despeito da queda de credibilidade do seu partido (PT) e das denúncias de corrupção contra seu governo. Destaque-se que, em 2006, houve um aumento maciço do número de entrevistados que consideraram a corrupção como o principal problema do Brasil (40\%), comparado com 2,7\% em 2002.

O que se pode deduzir destes resultados? Se, por um lado, plasmam-se opiniões positivas sobre os indicadores materiais, no que se refere à dimensão de "empoderamento" institucional, o resultado das avaliações desses indicadores é negativo, pois os ganhos na esfera material não se traduzem em ganhos de "empoderamento" institucional, na medida em que a avaliação da estrutura governamental é negativa. Isto contrasta com o desempenho pessoal do presidente Lula. Tais dados conduzem à idéia de que os pleitos eleitorais, de maneira geral, continuam a ser definidos mais do ponto de vista da figura do presidente do que da estrutura institucional.

\section{Considerações finais}

Este artigo examinou, inicialmente, pressupostos teóricos que sugerem que, após uma eleição presidencial, as orientações democráticas das pessoas se fortalecem. Entre outros fatores, argumentou-se que esse processo de "empoderamento" institucional resulta das lições apreendidas nas interações sociais com associações e organizações de mediação política. A escola deriva da socialização de um grupo que impõe uma estrutura normativa específica, uma construção social que é conduzida para o desenvolvimento e manutenção de atitudes democráticas de apoio ao governo.

No entanto, embora artigos recentes indiquem uma causalidade entre participação e capital social público, o estudo em dois pontos no tempo proposto aqui não confirmou esta associação. Os dados examinados sinalizam que a experiência em pleitos eleitorais não produz capital social institucional. Basicamente, a hipótese era que, se as premissas institucionalistas estivessem corretas, os cidadãos mostrariam um maior grau de apego às instituições políticas e aos setores públicos na eleição presidencial de 2006. Entretanto, tal expectativa não foi confirmada pelos dados. Se, por um lado, houve um aumento significativo do apoio difuso à democracia, o que é positivo, por outro lado, não se constatou um impacto positivo na constituição de capital social, nem institucional nem informal. 
BAQUERO, M. Eleições e capital social: uma análise das eleições presidenciais no Brasil...

Dessa maneira, embasados em resultados a respeito de uma série temporal (T1 e T2), não se pode concluir que "hábitos" recorrentes de participação eleitoral desemboquem, necessária e inevitavelmente, em processos de construção de capital social institucional. Os procedimentos poliárquicos, pelo menos com base nos dados analisados, parecem não ter tido impacto na direção esperada, ou seja, na solidificação de crenças positivas dos cidadãos a respeito de instituições políticas e gestores públicos; pelo contrário, os dados sugerem ser este um efeito negligenciável.

Quanto à construção de capital social informal, apesar de aqui terem sido exploradas poucas informações a este respeito, pode-se deduzir que tampouco houve um impacto significativo. Nessa dimensão, os únicos indicadores sobre capital social formal disponíveis nos questionários de 2002 e 2006 foram a filiação sindical e filiação em organizações profissionais. Nesses dois casos, para o período estudado, houve uma queda acentuada no número de pessoas filiadas a essas organizações (de 18,9\% em 2002 para 4,7\% em 2006 para sindicatos, e 12,8\% em 2002 para 1,5\% em 2006 em associações profissionais).

Quais são as implicações desses resultados para pesquisas sobre eleições e capital social no futuro? Em primeiro lugar, embora a associação entre eleições e capital social, teoricamente, tenha sentido, a análise indicou que as eleições não produzem capital social institucional em virtude de efeitos intervenientes, tais como qualidade de vida, comportamento político, socialização política, estágio de desenvolvimento econômico, magnitude de inclusão social e pobreza e comportamento ético dos gestores públicos. É plausível supor que esses fatores tenham alguma incidência na relação entre pleitos eleitorais e constituição de capital social institucional.

Em síntese, este artigo examinou se as predisposições democráticas convencionais e informais, por parte dos indivíduos, experimentaram aumentos como conseqüência de processos de habituação formal com procedimentos democráticos. Igualmente, avaliou se os processos eleitorais catalisaram comportamentos de apoio aos princípios democráticos. De maneira geral, essas hipóteses não encontraram sustentação na evidência empírica deste trabalho, sinalizando a necessidade de maior investimento na busca de subsídios que avaliem se instituições são eficazes na constituição de cidadãos críticos. 
OPINIÃO PÚBLICA, Campinas, vol. 13, n², Novembro, 2007, p.231-259

\author{
Referências Bibliográficas \\ ABRAMO, C. How much do Perceptions of Corruption Really tell us? Brasil: Transparência Brasil, \\ 2007.
}

AMES, B. and POWER, J. Parties and Governability in Brazil. In: WEBB, P. and WHITE, S. (Eds.). Party Politics in New Democracies. Oxford University Press, p.179-212, 2007.

ARNOLD, D. Congress, the Press, and Political accountability. New Jersey: Princeton University Press, 2004.

AYLLÓN, B. e GUERRERO, V. G. "Brasil, dos años de gobierno Lula." Política Exterior, vol.103, enero-feb. 2005.

BAQUERO, M. A vulnerabilidade dos partidos políticos e a crise da democracia na América Latina. Porto Alegre: Ed. da Universidade/UFRGS, 2000.

- Globalização e democracia inercial: o que o Capital Social pode fazer na construção de uma sociedade participativa. In: BAQUERO, M.; CREMONESE, D. (Org) Capital Social: Teoria e prática. ljuí: Editora ljuí, 2006.

BLINE, P. K. "Building Trust in government in the twenty- first century. Review of Literature and Emerging Issues." $7^{\text {th }}$ Global Forum on Reinventing Government. Vienna, Austria, 2006.

BOOTH, J. and RICHARD, P. B. "Civil society, political capital, and democratization in Central America". Journal of Politics. Volume 3, n. 60, p.780-800, Aug. 1998.

BOURDIEU, P. The Forms of Capital. In RICHARDSON, J. (ed.). Handbook of Theory and Research for the Sociology of Education. New York: Greenwood Press, 1986.

CARVALHO F.J. C. "Da morte política à consagração: Indagações sobre o significado da reeleição de Lula." BRASIL: Novos Estudos, 76, 2006.

CEPAL. "Comissão Econômica para América Latina. Objetivos de desarrollo del Milenio: una mirada desde América Latina y el Caribe." Santiago de Chile, 2005.

CITRIN, J. "Commment: the political relevance of trust in government." American Political Science Review. vol.68, n.3, p.973-988, Sept. 1974. 
BAQUERO, M. Eleições e capital social: uma análise das eleições presidenciais no Brasil...

COLEMAN, J. "Social capital in the creation of human capital." American Journal of Sociology. Suplement. p.95-120, 1988.

CRAIG, S. "Efficacy, trust and political behavior. An attempt to resolve a lingering conceptual dilemma." American Politics Quaterly, 7. p.225-239, 1979.

DAMATTA, R. "Reflexões sobre o público e o privado no Brasil: um ponto de vista perverso." Caderno de Ciências Sociais. Belo Horizonte, v.3, n. 3, p.51-59, abr.1993.

DYE, T. e ZIEGLER, H. The theory of democracy. Belmont California e Duxburg, 1970.

EASTON, D. A systems análisis of political life. New York : Wiley, 1965. Science, 1975

"A Re-Assessment of the concept of political support." British Journal of Political

FAORO, R. Os donos do poder: formação do patronato político brasileiro. vol.1. Porto Alegre: Editora Globo, 1979.

FINKEL, S. E. "Reciprocal Effects of Participation and Political Efficacy: A Panel Analysis." American Journal of Political Science, Vol.29, n.4, p.891-913, Nov. 1985.

FOUCAULT, M. Las palabras y las cosas. México: Siglo XXI Editores, 1977.

HUNTINGTON, S. A Terceira Onda: a democratização no final do século XX. São Paulo: Ática, 1994.

HOLANDA, S. B. de. Raízes do Brasil. Rio de Janeiro: José Olympio, 1980.

INEA. INEA Estudios Anticorrupción. Disponível em:

http://www.ineaestudiosanticorrupcion.org/page_1117909884039.htmn> 2006. Acessado em: 12 jun.2007.

KLESNER, J.L. "Social Capital and Political Participation in Latin America." Presented at 2002 Annual Meeting of the American Political Science Association. Boston, MA, Aug. 29-Sept.1. Retrieved May 10. 2003.

KLIKSBERG, B. Falácias e mitos do desenvolvimento social. São Paulo: Cortez, 2001. 
OPINIÃO PÚBLICA, Campinas, vol. 13, n², Novembro, 2007, p.231-259

.Como avanzar la participación en América Latina, el continente más desigual? Anotaciones estratégicas. Trabalho apresentado no XI Congresso Internacional del CLAD. Ciudad de Guatemala, p.1-29, 7.10 nov.2006.

LATINOBARÓMETRO, 2004 e 2005. Disponível em: <www.latinobarometro.org.> Acesso em: set. 2007.

LEAL, V. N. Coronelismo, enxada e voto: o município e o regime representativo no Brasil. São Paulo: Alfa- Ômega, 1978.

LINZ, J. J. and STEPAN, A. "Toward consolidated democracies." Journal of democracy. $\mathrm{n}^{\circ} .7$, p.14-33, 1996a.

Problems of transition and consolidation: Southern Europe, South America, and postcommunist Europe. Baltimore, MD/London: John Hopkins University Press, 1996b.

MARTINS, P. H. Cultura autoritária e aventura da brasilidade. In: BURITY, J. Cultura e identidade: perspectivas multidisciplinares. Rio de Janeiro: XX Editora, p.65-104, 2002.

MISHLER, W. e ROSE, R. "Trust, distrust and skepticism: Popular evaluations of civil and political institutions in pos-communist societies." The Journal of Politics. vol.59, $\mathrm{n}^{\circ} .2$, May. 1997.

NETTO, D. A. Paciência e eleições: Diplomacia, Estratégia Política. Brasília. nº.5, jan./maio. 2007.

NEWTON, K. "Trust, Social Capital, Civil Society, and Democracy." International Political Science Review, vol.22, n.2, p.201-214, 2001.

NUNES, E. A gramática política do Brasil: clientelismo e insulamento burocrático. Rio de Janeiro: Jorge Zahar, 1997.

PINHEIRO, P. S. EL-CHICHINI, M. e KAHN, T. Poverty, Marginalization, Violence and The Realization of Human Rights. New York: United Nations, General Assembly, World Conference on Human Rights, Preparatory Committee, Fourth Session, Geneva, Apr.1993.

POWER, T. J. and HUNTER, W. "Rewarding Lula: Executive Power, Social Policy, and the Brazilian Elections of 2006." Latin American Politics and Society, vol.49, nº.1, 2007.

PRZEWORSKI, A. Democracy and the market: political and economic reforms in Eastern Europe and Latin America. Cambridge: Cambridge University Press, 1991. 
BAQUERO, M. Eleições e capital social: uma análise das eleições presidenciais no Brasil...

PRZEWORSKI, A.; STOKES, S. C. e MANIN, B. Democracy, accountability and representation. Cambridge Studies in the Theory of democracy. Cambridge University Press, 1999.

PUTNAM, R. Comunidade e democracia: a experiência da Itália moderna. Rio de Janeiro, Fundação Getúlio Vargas, 2000.

PHARR, S., PUTNAM, R. e DALTON, R. (Orgs). Disaffected Democracies: What's troubling the trilateral countries? Princeton: Princeton University Press, 2000.

RENNÓ, L. "Notes on the Brazilian 2006 presidential elections: The winding road to democratic consolidation." Colombia Internacional, n. 64, p.154-165, 2006.

ROSE, R. and SHIN, D. C. "Democratization backwards: The problem of third-wave democracies." British Journal of Political Science, $\mathrm{n}^{\circ} .31$, p.331-354, 2006.

ROSE, R., MISHLER, W. and HAERPFER, C. Democracy and its alternatives: Understanding postcommunist societies. Baltimore, MD/London: John Hopkins University Press, 1998.

SARTORI, G. Parties and party systems. London: Cambridge University Press, 1976.

SELIGSON, A. "Civic associations and democratic participation in Central America: A test of Putnam's thesis." Comparative Political Studies, vol.3, n.32, p.342-62, May. 1999.

SHAFFER, S. D. "Multivariate Explanation of Decreasing Turnout in Presidential Elections, 1960-1976." American Journal of Political Science, vol.25, nº.1, p.68-95, Feb. 1981.

SHI, T. "Cultural values and political trust. A comparison of the People's republic of China and Taiwan." Comparative Politics, p.403-419, July. 2001.

VENTURI, G. “Determinações e significados da reeleição de Lula." Trabalho apresentado no Primer Congreso Latinoamericano de Opinión Publica WAPOR. Colonia del Sacramento. Uruguai, 2007.

TOQUEVILLE. A. A Democracia na América. São Paulo: Martins Fontes, 1998.

ZOVATTO, D. "América Latina después del 'rally' electoral 2005-2006: algunas tendencias y datos sobresalientes." Revista Nueva Sociedad. n.207, p.23-33, enero-feb. 2007. 